\title{
Isolation of Left Subclavian Artery with Tetralogy of Fallot-A Case Report
}

\author{
Anurag Agarwal, Nayem Raja, Akshay Chauhan, Muhammad Abid Geelani, Saket Aggarwal \\ Department of CTVS, Govind Ballabh Pant Institute of Postgraduate Medical Education and Research (Gipmer), New Delhi, India \\ Email: anurag_06041987@yahoo.co.in
}

How to cite this paper: Agarwal, A., Raja, N., Chauhan, A., Geelani, M.A. and Aggarwal, S. (2017) Isolation of Left Subclavian Artery with Tetralogy of Fallot-A Case Report. World Journal of Cardiovascular Surgery, 7, 11-15.

https://doi.org/10.4236/wjcs.2017.72002

Received: December 24, 2016

Accepted: February 4, 2017

Published: February 7, 2017

Copyright $\odot 2017$ by authors and Scientific Research Publishing Inc. This work is licensed under the Creative Commons Attribution International License (CC BY 4.0).

http://creativecommons.org/licenses/by/4.0/

\begin{abstract}
Background: Isolation of Left Subclavian Artery (LSCA) is a rare subset of Right Aortic Arch (RAA). It is diagnosed as nonvisualization of LSCA in catheterization study. Case Presentation: Here we report an unusual case of Tetralogy of Fallot (TOF) with right aortic arch with isolation of left subclavian artery (LSCA). Here LSCA originated from left pulmonary artery (LPA) through an atretic patent ductus arteriosus (PDA). There was nonvisualization of LSCA in catheterization study and it was confirmed by Computed Tomography (CT) angiography. Re-implantation of LSCA was done to left common carotid artery (LCCA) so that the left upper arm maintains a better flow in the future. Conclusion: Isolation of LSCA especially with TOF is a very rare entity. Re-implantation of LSCA to LCCA was done in view of weak pulses in left upper limb. Results were satisfactory in the follow up period.
\end{abstract}

\section{Keywords}

Isolated Left Subclavian Artery, Tetralogy of Fallot, Right Aortic Arch

\section{Introduction}

Isolation of Left Subclavian Artery (LSCA) from the right sided aortic arch is a very rare congenital anomaly and the least common type of Right Aortic Arch (RAA). Here the LSCA originates from the Left Pulmonary Artery (LPA) rather than the Aortic arch through the ductus arteriosus whether closed or patent [1]. Herein, we discuss a case of Tetralogy of Fallot (TOF) having sub aortic ventricular septal defect (S/A VSD), right ventricular outflow tract obstruction (RVOT) and pulmonary stenosis with isolated LSCA, who underwent successful Intra Cardiac Repair (ICR) for TOF and re-implantation of LSCA to Left Common Carotid Artery (LCCA). 


\section{Case Report}

An 8-year-old child presented with bluish discolouration of lips and fingers since 3 - 4 months of his birth along with features of recurrent Lower Respiratory Tract Infection (LRTI). There was no history of cyanotic spells, weakness of any limbs, pain or numbness. There was no history suggestive of cerebral, vertebral or basilar insufficiency. On examination, patient had mild cyanosis and clubbing of fingers. Pulses in the left upper limb were weaker as compared to that in the right upper limb; however there was no significant blood pressure difference (Right $(\mathrm{Rt})=90 / 52 \mathrm{~mm} \mathrm{Hg}$, Left $(\mathrm{Lt})=87 / 50 \mathrm{~mm} \mathrm{Hg})$. Saturation of oxygen (Spo2) in Rt upper limb was $87 \%$ and that in Lt upper limb was $84 \%$. Lower limb pressures and $\mathrm{O}_{2}$ saturation were also comparable with no significant differences. Cardio-vascular System (CVS) examination revealed a pansystolic murmur at apex. Chest X-ray showed a RAA with boot-shaped heart. Echocardiographic study revealed a typical anatomy consistent with TOF. There was sub aortic VSD with right ventricular outflow tract obstruction (RVOT) and pulmonary stenosis. Cardiac catheterization confirmed TOF with confluent and adequate Pulmonary Artery's (PA's). Aortogram confirmed the RAA with normal Right innominate, Right common carotid artery (RCCA) and Left common carotid artery (LCCA) with non visualization of LSCA; suggestive of isolation of LSCA (Figure 1). CT angiography confirmed the origin of LSCA from LPA (Figure 2) through an atretic Patent Ductus Arteriosus (PDA) and the LSCA was filling via a collateral artery originating from the descending aorta.

The child underwent total correction for TOF which included resection of hypertrophied muscle bundle in right ventricular outflow tract and Dacron patch closure of sub aortic VSD and pericardial patch augmentation of right ventricular outflow tract. The LSCA was reimplanted to the LCCA in an end to side fashion. The patient is doing well at follow-up after 3 months indicated by better blood pressure and bounding pulses in left upper limb.

\section{Discussion}

Isolated LSCA is the loss of connection of the LSCA from the aortic arch. It originates from the homolateral Pulmonary artery through a patent or closed ductus arteriosus. It is the least common type of RAA, occurring in $0.8 \%$ of a series of 298 RAA, reported by Stewart and associates [2] [3]. The embryological development of such a malformation can be explained by using the concept of "hypothetical double aortic arch plan" first given by Edwards in 1948 [4] [5]. There is interruption of the aortic arch at two levels, one between the left common carotid artery and the LSCA, and the second between the left ductus arteriosus and the aortic root. This results in a right aortic arch. The branches of the right aortic arch are in order of the left common carotid, the right common carotid, and the right subclavian arteries. The LSCA becomes detached from the aorta and is connected to the pulmonary artery by the ductus arteriosus either closed or open. In our case it was from an atretic Patent Ductus Arteriosus (PDA). The isolated LSCA mostly fills retrogradely from the left vertebral artery 


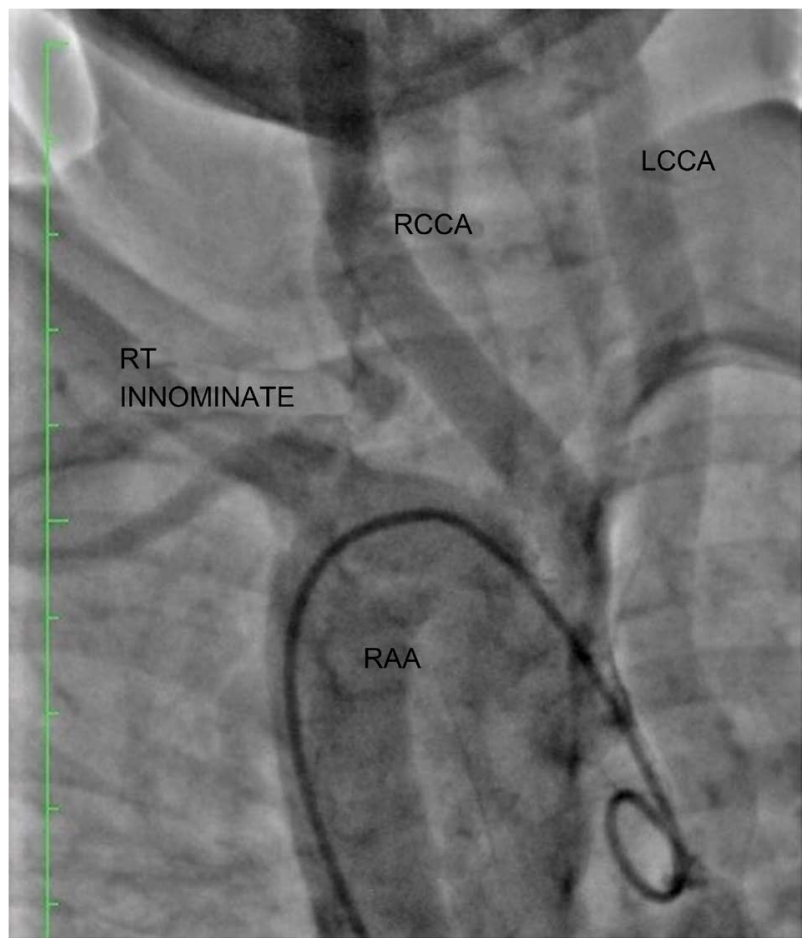

(a)

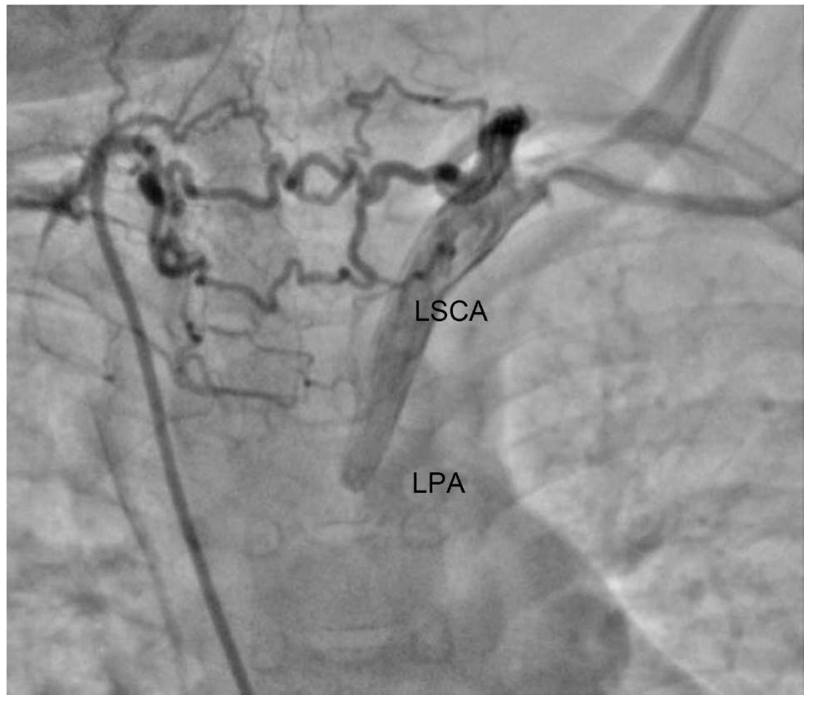

(b)

Figure 1. Cath study showing Rt Innominate artery, RCCA and LCCA originating from RAA with the non visualization of LSCA which itself indicate isolation of LCSA (a) and LSCA originating from LPA with collaterals from descending aorta (b).

usually causing "congenital Left subclavian steal" [6] [7]. In cases with patent ductus arteriosus a shunt between the pulmonary and systemic circulation is established; hence the retrograde vertebral blood flow supplies only the proximal LSCA before entering the pulmonary artery leading to pulmonary artery steal. Re-implantation seems to be an attractive option [8] [9] but catheter based embolization to abolish pulmonary steal by closure of PDA has also been described [10]. In our case, LSCA originated from LPA through an atretic PDA so there 


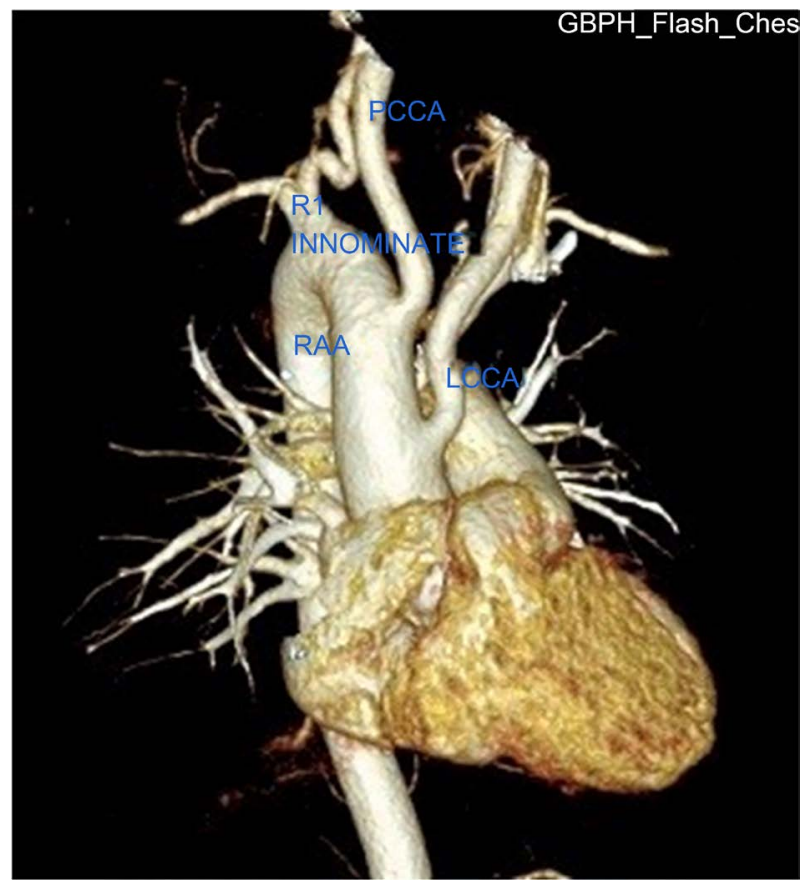

(a)

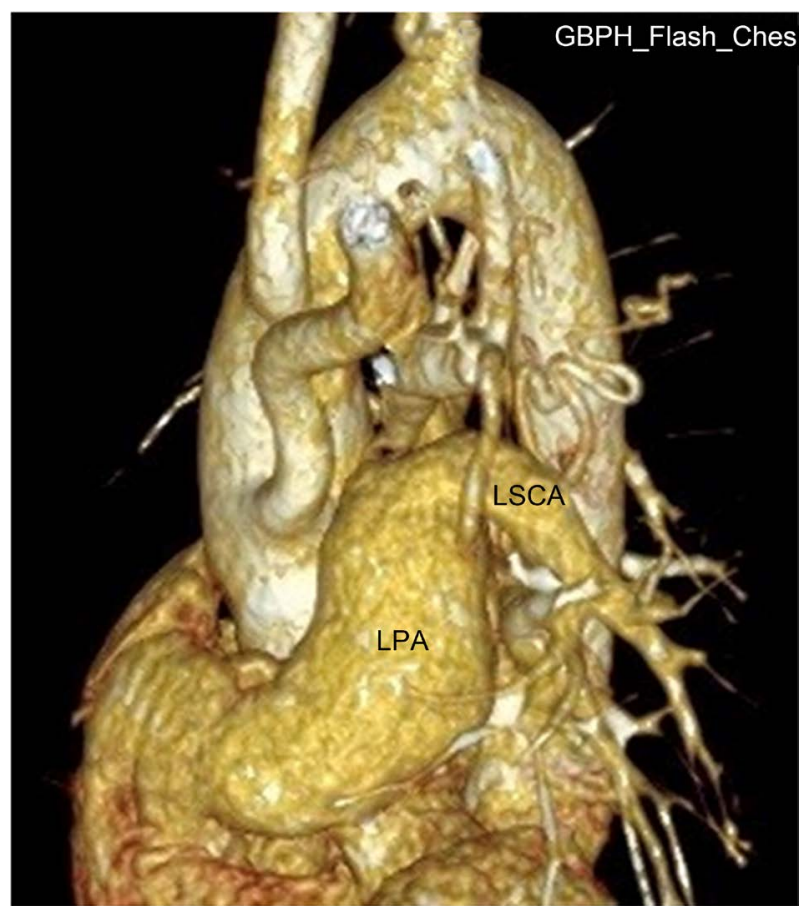

(b)

Figure 2. CT angiography 3D reconstruction showing Rt Innominate artery, RCCA and LCCA originating from RAA (a) and LSCA originating from LPA (b).

was no role of embolization as there was no pulmonary artery steal. It was supplied by collaterals from Descending Thoracic Aorta with no connection from the vertebral artery. So the patient did not have any vertebro-basilar insufficiency. In view of a weak pulse volume in left upper limb and anticipating symptoms in the limb as the child grows, we re-implanted the LSCA to LCCA. It was indicated by a 
better blood pressure and bounding pulses in the left arm in the follow up. Further study is needed to be conducted in similar cases and review should be done in order to accept re-implantation of LSCA as the line of management in such cases.

\section{Conclusion}

Isolation of LSCA especially with TOF is a very rare entity. As such isolation of LSCA doesn't alter the prognosis of the patient with TOF, but there always remains a dilemma regarding the management of isolation of LSCA. We had undertaken re-implantation of LSCA to LCCA in view of weak pulses in left upper limb. The results were satisfactory.

\section{References}

[1] Nath, P.H., Castaneda-Zuniga, W., Zollikofer, C., et al. (1981) Isolation of a Subclavian Artery. American Journal of Roentgenology, 137, 683-688. https://doi.org/10.2214/ajr.137.4.683

[2] Stewart, J.R., Kincaid, O.W. and Titus, J.L. (1966) Right Aortic Arch: Plain Film Diagnosis and Significance. American Journal of Roentgenology, 97, 377-389. https://doi.org/10.2214/ajr.97.2.377

[3] Leutmer, P.H. and Miller, G.M. (1990) Right Aortic Arch with Isolation of the Left Subclavian Artery: Case Report and Review of the Literature. Mayo Clinic Proceedings, 65, 407-413. https://doi.org/10.1016/S0025-6196(12)62540-3

[4] Edwards, J.E. (1948) Anomalies of the Derivatives of the Aortic Arch System. Medical Clinics of North America, 32, 925-949. https://doi.org/10.1016/S0025-7125(16)35662-0

[5] Mangukia, C., Sethi, S., Agarwal, S., Mishra, S. and Satsangi, D.K. (2014) Right Aortic Arch with Isolation of the Left Innominate Artery in a Case of Double Chamber Right Ventricle and Ventricular Septal Defect. Annals of Pediatric Cardiology, 7, 148-151. https://doi.org/10.4103/0974-2069.132500

[6] McMahon, C.J., Thompson, K.S., Kearney, D.L. and Nihill, M.R. (2001) Subclavian Steal Syndrome in Anomalous Connection of the Left Subclavian Artery to the Pulmonary Artery in d-Transposition of the Great Arteries. Pediatr Cardiol, 22, 60-62. https://doi.org/10.1007/s002460010155

[7] Ghon, A. (1908) Ueber eine seltene Entwicklungs-storung des Gefassystem. Verh Dtsch Ges Pathol, 12, 242-247.

[8] Lee, C., Kim, T.S., Lee, C.H. and Kim, S.J. (2010) Incomplete Isolation of the Left Innominate Artery in a Patient with Right Aortic Arch and Double Outlet Right Ventricle. Journal of Cardiac Surgery, 25, 232-234. https://doi.org/10.1111/j.1540-8191.2009.00978.x

[9] Gil-Jaurena, J.M., Ferreiros, M., Zabala, I. and Cuenca, V. (2011) Right Aortic Arch with Isolation of the Left Innominate Artery Arising from the Pulmonary Artery and Atrial Septal Defect. The Annals of Thoracic Surgery, 91, 303. https://doi.org/10.1016/j.athoracsur.2010.06.015

[10] Jones, T.K., Garabedian, H. and Grifka, R.G. (1999) Right Aortic Arch with Isolation of the Left Subclavian Artery, Moderate Patent Ductus Arteriosus, and Subclavian Steal Syndrome: A Rare Aortic Arch Anomaly Treated with the GianturcoGrifka Vascular Occlusion Device. Catheterization and Cardiovascular Interventions, 47, 320-322. https://doi.org/10.1002/(SICI)1522-726X(199907)47:3<320::AID-CCD15>3.0.CO;2-V 
Submit or recommend next manuscript to SCIRP and we will provide best service for you:

Accepting pre-submission inquiries through Email, Facebook, LinkedIn, Twitter, etc. A wide selection of journals (inclusive of 9 subjects, more than 200 journals)

Providing 24-hour high-quality service

User-friendly online submission system

Fair and swift peer-review system

Efficient typesetting and proofreading procedure

Display of the result of downloads and visits, as well as the number of cited articles Maximum dissemination of your research work

Submit your manuscript at: http://papersubmission.scirp.org/

Or contact wjcs@scirp.org 